\title{
Electrochemical Properties of Olivine-Type LiFePO4/C Cathode Material for Lithium Ion Batteries
}

\author{
Tong Zhang, Zi Yang, Li Wang, Xing Zhao, Quan-Chao Zhuang* \\ School of Materials Science and Engineering, China University of Mining \& Technology, Xuzhou \\ 221116, China \\ *E-mail: zhuangquanchao@,126.com
}

doi: $10.20964 / 2018.09 .30$

Received: 3 June 2018 / Accepted: 4 July 2018 / Published: 5 August 2018

\begin{abstract}
Although olivine $\mathrm{LiFePO}_{4}$ has been widely utilized as a cathode material for lithium ion batteries, there is still debate regarding the interpretation of the Nyquist plots of $\mathrm{LiFePO}_{4}$ electrodes in the literature. In the present paper, the impedance spectra for lithium ion de-insertion and insertion in $\mathrm{LiFePO}_{4}$ electrodes, with different percentages of graphite material serving as the conductive additive, were obtained at different potentials during the first charge-discharge cycle. The results reveal that the characteristic Nyquist plot of $\mathrm{LiFePO}_{4}$ electrodes is strongly influenced by the content of the conductive additive. With increasing conductive content in the $\mathrm{LiFePO}_{4}$ electrode, the characteristic Nyquist plot changes from a semicircle and an inclined line to two semicircles and an inclined line. The fundamental reason for this new phenomenon and the ascription of the time constants in the Nyquist plots of the $\mathrm{LiFePO}_{4}$ electrodes are analyzed in detail based on simulated results of the experimental EIS data.
\end{abstract}

Keywords: lithium ion batteries, $\mathrm{LiFePO}_{4}$, electrochemical impedance spectroscopy, conductive additive,

\section{$\underline{\text { FULL TEXT }}$}

(C) 2018 The Authors. Published by ESG (www.electrochemsci.org). This article is an open access article distributed under the terms and conditions of the Creative Commons Attribution license (http://creativecommons.org/licenses/by/4.0/). 